$5-19-2020$

\title{
When and how the law is effective in reducing the practice of FGM/C: A cross-border study in Burkina Faso and Mali
}

Josephine Wouango

Susan L. Ostermann

Daniel Mwanga

Population Council

Follow this and additional works at: https://knowledgecommons.popcouncil.org/departments_sbsr-rh

Part of the International Public Health Commons, and the Social and Behavioral Sciences Commons How does access to this work benefit you? Let us know!

\section{Recommended Citation}

Wouango, Josephine, Susan L. Ostermann, and Daniel Mwanga. 2020. "When and how the law is effective in reducing the practice of FGM/C: A cross-border study in Burkina Faso and Mali," Policy brief. Nairobi: Population Council. 


\section{When and how the law is effective in reducing the practice of FGM/C: A cross-border study in Burkina Faso and Mali}

The Evidence to End FGM/C programme consortium generates evidence to inform and influence investments, policies, and programmes for ending female genital mutilation/ cutting in different contexts.

Population Council Lead Institution

Africa Coordinating Centre for the Abandonment of Female Genital

Mutilation/Cutting, Kenya (ACCAF)

Global Research and Advocacy Group, Senegal (GRAG)

MannionDaniels Ltd. (MD)

Population Reference

Bureau (PRB)

University of Washington (Prof. Bettina Shell-Duncan)

University of California, San Diego (Dr. Gerry Mackie)

Funded by

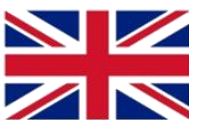

\section{Introduction}

Female genital mutilation/cutting (FGM/C) is recognised globally for being associated with risks to both the physical and psychological health of girls and women; it is also considered to be a violation of human rights. At present, an estimated 200 million girls and women in 30 countries have undergone $\mathrm{FGM} / \mathrm{C}$ and as many as 30 million under-15 girls are at risk (UNICEF 2016). A common policy response to $F G M / C$ is to enact laws and enforce criminal prohibitions.

In Burkina Faso and Mali, the type of FGM/C practised is largely the "cut, flesh removed" variety, which represents WHO Types I and II. In 1996, Burkina Faso passed a law punishing $\mathrm{FGM} / \mathrm{C}$. This law was revised in 2018 with a shift towards additional imprisonment and fines. In Mali, the government has a strategy in place to end FGM/C, but, to date, it has not adopted a law that specifically criminalises FGM/C. In Burkina Faso, national statistics suggest that there has been a decline among women aged $15-49$ years $(76 \%$ in 2010 to $67 \%$ in 2015) and girls aged 0-14 years $(13 \%$ in 2010 to $11 \%$ in 2015$)$ (INSD 2012, 2015). In Mali, FGM/C prevalence is thought to be higher, with about $91 \%$ of women aged $15-49$ years reportedly cut as of 2012-13 (INFOStat/Mali and ICF International 2014).
This policy brief summarises key

findings from a cross-border

study of two neighbouring

countries: Burkina Faso, which

has a strong FGM/C law, and Mali,

which has no specific FGM/C law

(Wouango, Ostermann, and

Mwaya 2020). The aim of the

cross-border study was to explore

and compare attitudes and

tendencies towards obeying the

law and continuing FGM/C

practises and to understand the

effectiveness of criminal law in

combatting FGM/C in both

countries.

\section{Methods}

This study used a mixed-methods design. Data were collected in six paired villages along the Burkina Faso-Mali border, a place with high FGM/C prevalence among dominant ethnic groups. Each paired village was chosen to reflect the same majority ethnic group (the Bobo in FaramanaBF/Koury-Mali; the Senoufo in KolokoBF/Finkolo-Mali, and the Bwaba in Tansila-BF/Boura-Mali). Our target population was both men and women, over 18 years of age. Our quantitative study randomly sampled participants ( $n=1209)$, and included an innovative list experiment method to assess respondents' future intention to practise FGM/C. This technique allows 
researchers to ask about sensitive topics to help overcome the social-desirability bias often associated with self-reporting of socially unacceptable activities by hiding responses from the researcher and any other party.

The qualitative component of the study involved Key Informants Interviews (KIls) $(n=60)$ and Focus Group Discussions (FGDs) $(n=24)$. Key informants were purposively selected from various positions within chosen communities and included community and religious leaders, local NGO representatives and government officials such as health workers, prefects, teachers, and social workers. All key informants were aged 18 years or older. FGDs were conducted among men and women of varying ages split into four groups: younger men (aged 18-34 years), older men (35 years and older), younger women (aged 18-34 years), and older women (35 years and older). Each focus group consisted of between 6-8 persons. Participants were all community members and were recruited by the qualitative team leaders with the support of community facilitators. Ethical approval was obtained from the Mali Ministry of Health, Burkina Faso Ministry of Health, and the Population Council's Institutional Review board.

\section{Findings}

What do participants know about the legality or illegality of FGM/C?

The vast majority of respondents think that FGM/C is illegal $(87 \%$ of all respondents in Burkina Faso and $80 \%$ in Mali). The results in Burkina Faso were consistent with previous studies (CNLPE 2006). The Mali results were surprising, in that Mali does not have a specific law that criminalises and punishes FGM/C practise. Radio was cited as the main source of information about the law in both countries for the majority of the study participants. $\mathrm{FGM} / \mathrm{C}$ information on the radio is conveyed by government officials such as health workers, judges, and social workers, as well as by local NGOs and local leaders. In Burkina Faso, these actors play a key role in supporting the actions of the National Committee to Fight Against the Practice of Excision (CNLPE). The type of messaging is mainly awareness-raising through explaining the health consequences of $\mathrm{FGM} / \mathrm{C}$, informing about the law and its penalties, and the possibility of reporting cases anonymously through the "SOS excision" free hotline. For example, the media cover all mobile courts' public hearings which makes the process well-known by the population, even those in remote areas.

Additionally, the CNPLE uses the radio to explain the possibilities of repairing the after-effects of excision and obstetric fistula. Local radio is the most accessible media to people in our study areas sites because it broadcasts in the shared local language Dioula. Participants citing radio as the main source of information about the law in Mali may be partly explained by a cross-border diffusion of anti-FGM/C messaging from Burkina Faso.

"[...] It was said on TV and radio by doctors that girls should not undergo excision."-Male, KII, Koury, Mali

"There are radio broadcasts where the judge even comes to explain certain provisions of the law to the public."-Female, KII, Tansila, Burkina Faso

\section{What motivates people to obey or disobey a law prohibiting FGM/C?}

Respect for the law motivated just over half of all respondents to report obeying the laws themselves: $54 \%$ reported motivation to obey statutory law flows from a sense of legal obligation and from believing others behave similarly (54.4\% in Burkina Faso and $53.6 \%$ in Mali). Also $84 \%$ of respondents in Burkina Faso and $77 \%$ in Mali stated they would NOT continue FGM/C if everyone else in their community abandoned the practise. This reinforces the importance of social norms in determining FGM/C behaviour, as highlighted by two KII respondents below:

\section{Q: What would happen to a family that decides not to cut their daughter?}

"Well, it will be a social isolation. Since you belong to a community that has its laws, and when you challenge these laws, it's like you're putting yourself out of the community. So, it's mostly that isolation, your way of seeing and doing things set you aside of the community. You have refused to follow the community rules and that's what can put you aside." - KII, Finkolo, Mali

"Nothing is going to happen to them in our community. Nowadays there are a lot of households where the girls under the age of 20 are not cut. There are so many girls who are in this situation now, so nothing will happen to them". - KII, Koloko, BF 
How has Burkina Faso's FGM/C law been implemented?

The law has been enforced through a variety of different approaches. Mobile courts have held prosecutions and sentencing publicly within communities, cases can be reported through an SOS Excision Hotline, and there is strong collaboration among stakeholders, political will, effective communication, and awareness-raising in local languages. This multifaceted approach is possible through the strong engagement of security forces and religious and local leaders. The CNLPE in Burkina Faso has undertaken a strategy called an "approach through community leaders" which consists of engaging respected community and religious leaders to adhere to and convey the abandonment messaging. The records of their engagement and messages are shared over radio,

TV, and in newspapers and on CNLPE social media webpages. For example, the Moro Naba in Ouagadougou who is the supreme king of the Mossi people in Burkina Faso is a champion for abandoning FGM/C. Messaging has also focused on the health consequences of the practise and health workers are trained and involved as key players in very remote areas. However, interventions specifically addressing cross-border FGM/C are lacking. There is no strong coordinated intervention between the two countries.

Respondents also frequently mentioned health workers as a source of their knowledge of antiFGM/C law (in Burkina Faso), as well as of the many negative health consequences of the practise (in both countries).

"We do not do it anymore because the doctors told us not to." - Male, KII, Faramana, Burkina Faso

"I learned with the health workers who told us not to do it anymore because the law bans cutting the girls."-Female, FGD 35+, Faramana, Burkina Faso

"The doctors [health workers] said on the radio and on the TV that we should not cut the girls anymore."-Male, FGD 35+, Koury, Burkina Faso

"The health workers told us that cutting girls is not a good thing and to stop it. They even arrest people for that. Nowadays, some people do it secretly, for others the husband agrees, for others the husband doesn't agree." - Female, FGD 18-34, Boura, Burkina Faso
What factors hinder FGM/C abandonment? Participants provided various reasons to justify FGM/C continuation-culture/tradition, social reasons (marriageability), perceived health benefits, pressure from elders, regulation of women's sexual desire, social sanctions such as shaming, and consequences within the community and one's reference network. Respect for culture and religion, in particular, have a significant effect on people's behaviour: some respondents believe that $\mathrm{FGM} / \mathrm{C}$ is permitted by their religion (15.8\% in Burkina Faso and 18.3\% in Mali) and customs (20.7\% in Burkina Faso and $22.5 \%$ in Mali).

$\mathrm{FGM} / \mathrm{C}$ is reportedly undertaken across the Burkina Faso and Mali border (UNICEF 2016) as well as across the borders with Côte d'Ivoire, Niger, and Ghana (GRIGED 2008), hindering abandonment.

"I know that it is at the weddings that people often say that this girl is not cut. There are girls who have even been sent back to their parents because they were not cut. This means that for many parents, it is the same thing that pushed them to cut their daughters. They do not want that one day her husband repudiates her because she is not cut."-Male, KII, Koloko, Burkina Faso

\section{Recommendations}

The government of Burkina Faso should sustain its innovative approaches to enforcing the antiFGM/C law including mobile community courts that raise awareness by condemning cutters and their accomplices publicly; a free telephone line to report cases, managed by security forces placed at the disposal of the SP/CNLPE; an effective lobbying and advocacy strategy through engagement of high-level community and religious leaders; trainings of the judicial actors, security agents, health workers; community patrols by security forces to sensitise community members; close partnerships with national and local media that cover all community court hearings and extensively broadcast the national anti-FGM/C activities and messaging in French and local languages; translation of the law into four main local languages and distributed in the communities through local organisations; commitment of former cutters through public 
declarations of FGM/C abandonment; and the CNLPE's leading role in coordinating all the actions in partnership with many stakeholders. Specific additional recommendations include:

- Continue to involve health workers and support them with resources and capacitystrengthening activities. They are agents of change who have had a positive influence on women in our study communities.

- Implement and strengthen international coordination to eliminate cross-border $\mathrm{FGM} / \mathrm{C}$. Our results revealed that regional cooperation is necessary to curb FGM/C in the border area. To date, no mechanism exists to address this issue. A regional law that intensifies efforts at the community level across the border should help to reduce the underground practise of cross-border $\mathrm{FGM} / \mathrm{C}$.

- The government in Mali should move forward to adopt and enforce a specific law criminalising $\mathrm{FGM} / \mathrm{C}$ and could learn from the experience of Burkina Faso. It should develop strategies to persuade powerful and influential religious and community leaders to encourage abandonment among their followers, and provide resources and support to health workers, who seemingly playing a key role in the shift towards abandonment.

\section{References}

GRIGED. 2008. Pratique transfrontalière de l'excision: Etat des lieux et évaluation des actions dans les zones frontalières $d u$ Burkina Faso, de la Côte d'Ivoire, du Ghana, du Mali et du Niger. Study Report. New York: UNIFEM.

INFO-Stat/Mali and ICF International. 2014. Enquête démographique et de santé au Mali 2012-2013. Rockville MD: CPS, INSTAT, INFO-STATE, and ICF International.

Institut National de la Statistique et de la Démographie (INSD), Ministère de l'Économie et des Finances, Burkina Faso. 2012. Enquête démographique et de santé et à indicateurs multiples (EDSBF-MICS IV) 2010. Calverton, MD: ICF International.

. 2015. Enquête multisectorielle continue. Burkina Faso: INSD

National Committee to Fight the Practice of Excision (CNLPE). 2016. Evaluation de l'impact des activités de promotion de l'élimination de la pratique de l'excision de 1990 à 2015 au Burkina Faso. Final Report. Ouagadougou: Ministry of Family, National Solidarity and Women.

UNICEF. 2016. Female Genital Mutilation/Cutting: A Global Concern. New York: UNICEF.

Wouango, J., S. Ostermann, and D. Mwanga. 2020, "When and How Is the Law Effective in Reducing the Practice of FGM/C. A CrossBorder Study in Burkina Faso and Mali," Evidence to End FGM/C: Research to Help Girls and Women Thrive. New York: Population Council. 